\title{
Mobilities, moorings and boundary marking in developing semantic technologies in educational practices
}

\author{
Richard Edwards $^{\mathrm{a} *}$, Fran Tracy ${ }^{\mathrm{b}}$ and Katy Jordan ${ }^{\mathrm{c}}$ \\ ${ }^{a}$ School of Education, University of Stirling, Stirling, UK; ${ }^{b}$ Faculty of Education, \\ Community and Leisure, Liverpool John Moores University, Liverpool, UK; ${ }^{c}$ Centre for \\ Applied Research in Educational Technologies, University of Cambridge, Cambridge, UK
}

(Received 5 January 2011; final version received 12 September 2011)

\begin{abstract}
While much attention has been given to the changing spaces of education introduced by new technologies, the impact of spatial theory on the discussion of such education is less well developed. Drawing upon empirical evidence from the Ensemble research project, this article examines spatially some of the possibilities and constraints that arise in the introduction of semantic technologies into case-based learning in higher education. While the affordances of the semantic web provide a technological basis for the development of flexible tools and associated pedagogies in ways that could enhance case-based learning, there are many tensions in this process. In this article, we draw upon certain aspects of spatial theory to examine the ways in which the mobilities and openings made possible by the introduction of semantic technologies also entail mooring and boundary marking in order to give the technologies specifically educational purposes. We suggest how educational practices can be considered theoretically as spatial orderings and some of the implications.
\end{abstract}

Keywords: semantic technologies; spatial theory; mobilities; moorings; boundary marking; higher education

... if you click on a bubble or a little image ... wooosh! You can move into sort of a parallel universe of electronic hyperspace. (University lecturer)

\section{Introduction}

Over the years, there has been much discussion of the impact of the internet and new forms of data sourcing and communication for education and the ways in which virtual learning breaks down the 'spaces of enclosure' (Lankshear, Peter, and Knobel 1996; Edwards and Usher 2008) of the institution, classroom, and curriculum. From virtual worlds and simulations to new search and visualisation tools, to authoring and mashing, to blogging and networking, to programmed learning and email, to interactive boards and technological toys, the potentialities of technologies for education seem expansive. Yet alongside this sit the inevitable limitations of curriculum, assessment and audit regimes, existing cultures of teaching and learning, the humanistic values embedded in much education that give primary value to the face to face, and resource issues. Technological possibilities and the constraints of education as an institution are constantly in play. This article attempts to explore

*Corresponding author. Email: r.g.edwards@stir.ac.uk 
these tensions within the context of a research project - Ensemble - that is seeking to examine the potential of semantic technologies for the development of case-based learning in higher education in the United Kingdom.

Case-based learning is a common pedagogical model in learning environments in which the subject matter is complex, controversial or rapidly changing, where problem-solving is important, and in which multiple perspectives and interpretations need to be understood. Semantic technologies provide the possibility for machinereadable reasoning and representation of data, thereby reducing the effort of searching by humans. The affordances of the semantic technologies therefore provide a basis for the development of flexible tools and associated pedagogies in which knowledge is developed, represented, adapted, and then translated in ways that could enhance educational practices. While semantic technologies are revolutionising the long-term preservation and retrieval of data from large and heterogeneous information sources, they have not been much mobilised in advanced education settings that employ case-based learning. The aim of the Ensemble project has been to undertake research and development activities that contribute both to the understanding of pedagogical practice in case-based learning across disciplines and to the development of semantic technologies and educational environments.

The project has been working with groups of lecturers and students in three diverse higher education sites and a number of disciplinary settings. The research is addressing similarities and differences in the conceptualisation, construction and application of cases, the role of case-building as an individual and group activity, and ways in which semantic technologies can support, enhance and transform these learning activities through the provision of easy-to-use and flexible software tools and interfaces. In this article, we refer to data from a number of different programmes - in particular, undergraduate courses in Plant Sciences and in Dance - to explore some of the tensions between possibilities and constraints in the uptake of these technologies for pedagogic purposes.

To theoretically frame this tension we draw upon spatial theory. While much attention has been given to the changing spaces of education introduced by new technologies, and the use of spatial metaphors in the framing of educational practices, the impact of spatial theory on the discussion of such education is less well developed (Nespor 1994; Edwards et al. 2004; Edwards and Usher 2008; Ferrare and Apple 2010). With that comes a tendency towards cyber-utopianism and cyberdystopianism, wherein space itself is left unexamined as simply a different context, container or backcloth for curriculum and pedagogy. In this article, we want to draw upon aspects of spatial theory to examine the ways in which the mobilities and openings made possible by the introduction of semantic technologies also entail mooring and boundary marking in order to give the technologies specifically educational purposes. We also want to suggest that framing education as spatial orderings raises important questions about certain dominant discourses that focus on learning and teaching as the focus of educational debate.

The article is in four parts. First, we outline a typology of spatial theories; in particular, the contemporary uptake of theories of (im)mobilities, which we draw upon within this article. Work on (im)mobilities has developed from the interplay of post-structuralist theory with complexity and actor-network theory. Second, we explore the concept of cyberspaces and some of the debates and issues surrounding the practices that have been developed. While the concept of cyberspaces is not a shared one in the discussion of technologically mediated educational environments, 
not least because it can result in a detachment of their materiality from consideration, we use it here as it points to precisely the theoretical focus of this article; that is, spaces. Third, we explore data from the Ensemble project. Finally, we suggest that rather than consider education as focused on practices of learning and teaching, we could more fruitfully consider it as spatial orderings or (im)mobile assemblings in the enactments of curriculum and pedagogy.

\section{Spatial theory - mobilities and moorings}

Spatial theory is used by both educationalists and geographers to research education following what is sometime referred to as the spatial turn in social sciences in the 1990s. In such approaches, space is not considered a static container into which teachers and students are poured, or a backcloth against which action takes place, but a dynamic multiplicity that is constantly being enacted by simultaneous practices so far. Space is not to be considered simply an object of study, as, for instance, in examining how classroom spaces are designed and used. It is also more critically a theoretical tool for analysis. Issues for education that are often identified include how spaces become learning spaces, how they are constituted in ways that enable or inhibit learning, create inequities or exclusions, or open and limit possibilities for new practices and knowledge. Particularly in new educational arrangements incorporating rapidly developing media and communications technologies, the ordering of space-time has become a critical influence on and a way of analysing curriculum and pedagogy as part of and as contributory to globalisation. Increasingly, network metaphors have come to the fore to help frame the understanding of these processes. Spatial theories raise questions about what knowledge counts, where, how it emerges in different time-spaces, how subjectivities are negotiated through movements and locations, and how education is enmeshed as and in the making of spaces. However, despite the consideration of spatial issues and the use of spatial metaphors, there has been little explicit exploration of spatial theory in education (Gulson and Symes 2007).

Soja and Hooper $(1993,197)$ pointed out almost two decades ago that there is a general agreement that "space makes a difference in theory, culture and politics". There is a consequent bringing to the fore of the significance of "the spatiality of human life' and recognition of the difference that space makes. Space is seen as having been under-theorised and marginalised in relation to the previous emphasis on time and history. As a feature of the valorisation of time, space was constructed as neutral, fixed and immobile, unrelated to the social and without impact on the formation of subject identity and biography. Space was framed as a container or backcloth within or against which activity took place through time.

In recent decades, there has been a shift from considering space as universal and abstract in favour of conceptions that bring to the fore the enacted, turbulent, entangled and hybrid nature of space. However, it would be inappropriate to conclude from this that the focus on time has now been simply replaced by a focus on space. It is more helpful to think of it in the way Massey $(1993,155)$ does: "space is not static (i.e. time-less), nor time spaceless ... spatiality and temporality are different from each other but neither can be conceptualised as the absence of the other". As she goes on to point out, we need to think in terms of 'space-time', of a conception and actuality of time and space as inseparable and interactively relational, as, for example, we witness in school timetables and their organisation of 
spaces, times, bodies and artefacts. Or, as Jones, McLean, and Quattrone (2004) suggest, we may need to consider spacing and timing as actions, verbs rather than nouns, thus pointing to the ways in which they are both performative and performed rather than existing in some assumed state of being.

Broadly, we can identify four threads in contemporary interest in space in social theory. None is entirely discrete from the other and they have emerged from debates within and between the different framings. Each is subject to multiple interpretations. First, there is a political economy framing of space. This draws upon Marxist traditions of analysis, in particular those emerging in Western Europe, post-Gramsci. It is associated with such writers as Lefebvre (1991) and Harvey (1989). Such analyses focus on the orderings and representations of space as manifestations of changing economic conditions and its effects on everyday life. Development, industrialisation, urbanisation, globalisation and the inequalities they engender through the re-orderings of production and consumption are key themes in such analyses. Second, there is a feminist framing of space. Emerging from the analysis of the public-private binary as unequally gendered and associated with writers such as Massey (1994, 2006), a key focus is the analysis of the gender inequalities in changing orderings of space-time and, more broadly, the power-geometries of their particular orderings.

Third, there is broadly what we can refer to as the post-structuralist framings of space, emerging from the work of, for instance, Foucault, Deleuze and Guattari, and associated with writers such as Soja (1989). These analyses have been influenced by the linguistic and culturalist turns in social theory from the 1980s and the associated form of 'post-'theorising. Deleuze and Guattari's (1988) notions of the rhizome as a way to deterritorialise a contrast between striated spaces - closed and bounded - and smooth spaces - open and nomadic - has been increasingly influential. Key themes in such approaches are questions of subjectivity, representation and power. Associated with this thread are attempts to examine the spaces of marginalised others, with concern being focused on, for instance, margins (Spivak 1993), interstitial third space (Bhabha 1994), nomadism (Braidotti 1994) and diaspora space (Brah 1996). In such approaches, there is often an implied set of binaries between mobility, openness, cosmopolitanism and freedom, on the one hand, and place, closure, parochialness and constraint on the other.

Fourth, there is what is referred to as a materialist (re)turn in framings of space (Anderson and Wylie 2009). This turn attempts to address what are considered some of the limitations of the other three threads, but is itself caught up in the debates over how we frame matter and the material - a matter of concern across the social and natural sciences (Barad 2007; Bennett 2010). The materialist turn takes many forms, some of which might be seen as rejections of 'theory' articulated in post-structuralist framings of space. For our purposes, the significant work in this thread is associated with the (im)mobilities paradigm (Urry 2007), in part, influenced by post-humanist and non-representationalist theories, such as actor-network and complexity theories, within which particular spaces are viewed as emergent network effects (Murdoch 1998). This work has focused on space as material (dis) orderings, as enactments and performative. Here there is a movement away from framings that assume and reproduce traditional subject-centred epistemologies wherein human intention and action is assumed and given primacy, as 'human life ... is never just human' (Urry 2007, 45). Spatial orderings are not about human 
subjects per se, but are material assemblages of subjects-objects that interrupt and affect, question and promise.

There are those who pursue notions of smooth and striated space, de-territorialisation and re-territorialisation and emerging connectivities as pointing to the significance of mobilities, flux and movements in framing understanding of socio-spatial relations (Urry 2007; Watts and Urry 2008). This work seeks to thread a route between sedentary views of space that assume value and authenticity in notions of place and the local and what might be considered a postmodern grand narrative of the superiority of mobility or nomadism over other forms of life. In relation to the former:

sedentarism treats as normal stability, meaning, and place, and treats as abnormal distance, change, and placelessness ... Such sedentarism locates bounded and authentic places or regions or nations as the fundamental basis of human identity and experience and as the basic units of social research. (Sheller and Urry 2006, 208-209)

The mobilities theoretical framing can be seen as contributing to the materialist turn in geography, as "there are hybrid systems, 'materialities and mobilities' that combine objects, technologies, socialities and affects out of which distinct places are produced and reproduced" (Hannam, Sheller, and Urry 2006, 14). Here, as with smooth and striated spaces, place is not bounded or separated from flux and networks but arise from them and vice versa.

Sheller and Urry (2006) identify six threads of theory informing mobilities research: the spatial turn in the social sciences, science and technology studies, the work of Simmel, the recentring of the corporeal body as a matter of concern, the topologies of social networks; and complexity theory. These provide a sophisticated set of resources through which to rework spatial framings generally, and the analysis of the semantic technologies in education more specifically. A focus on mobilities points us towards a tracing of the movements, relations and networks of objects, people, information and images, and the ways in which flux is regulated, made possible and constrained, as "all mobilities presuppose large scale immobile infrastructures that make possible the socialities of everyday life" (Urry 2007, 19). For instance, computers require power stations to make electricity, aircraft require airports and timetables, mobile phones require transmitter masts, rights to travel are restricted for many by laws and borders, and cars require petrol stations.

Rather than starting analysis from a space out of which objects move, this approach aims to map mobilities and the ways in which spaces are moored, bounded and stabilised for the moment, and the specific (im)mobilities associated with such moorings. We might take such spaces for granted - as, for instance, universities - but a mobilities analysis would examine the ways in which such spaces are enacted and become sedimented across time. These mobilities, immobilities and moorings point to the entanglement and complex patterning of spaces, and the requirement to examine particular empirical tracings of relational and network enactments of space (Murdoch 1998) rather than producing some overarching spatial explanation. We are therefore interested here in what Massey (1994) referred to as the power geometries of everyday life. This has implications for how we might research education, and the extent to which curriculum and pedagogy are moored and bounded through particular enactments and gatherings of relations. The mobilities approach points to the need not only to challenge any notion of treating cyber- 
spaces as if they are simulacra of a classroom, but also to challenge the very notion of the classroom as a container for curriculum and pedagogy.

For Hannam, Sheller, and Urry $(2006,4)$, the focus on mobilities is not a simple celebration of a privileged mobile existence, therefore, but a way to analyse how (im)mobilities are enacted and the power exercised through such enactments: "the spatialities of social life presuppose, and frequently involve conflict over, both the actual and the imagined movement of people from place to place, event to event". And not simply people, but also objects, goods, services, news, information, power within which can be exercised at a distance through the use of new technologies.

It is important to bear in mind the connections between the four threads of spatial theorising, as, for instance, in different ways, both Harvey and Soja were influenced by Lefebvre's work on urbanisation. Lefebvre himself influenced and was influenced by the Situationists, like Debord, who have also influenced strands of 'post-'theorising. He was also more interested in the material than in debates about epistemology. Indeed there is much ongoing debate about how to interpret Lefebvre and the diverse uptakes of him in the English language (Shields 1999; Elden 2001). Massey was initially much influenced in her writing by Marxist feminism, although this shifted somewhat with time. Some of those taking up the materialist turn might be said to be extending the range of post-structuralist geographies by drawing upon theories of matter emerging from sub-atomic physics. Many contemporary cultural geographers and social theorists draw upon the different threads in making their own spatial ropes, as is represented in the shift to focus on (im)mobilities rather than place in some spatial framings (Sheller and Urry 2006). In this context, what sorts of spaces are cyberspaces?

\section{Cyberspaces - relational, mobile, bounded}

Cyberspaces have been the subject of much research. The use of the plural in cyberspaces is deliberate, as there is a tendency to homogenise what is a diverse and multiple set of practices and possibilities. Integral to the discussion of spaces is inevitably the influence of the new technologies and forms of connectedness and mobility. Web technologies can be framed in a number of ways. They are tools for communicating, ordering goods and services, organising lives. They reconfigure the possibilities for relating, supporting the increased absent-present forms of sociality through the technoscapes of, for instance mobile telephones and online social networking (Licoppe 2004). For us, cyberspaces do not represent the closed spaces of virtual worlds, but the complex webs of material practices through which technologically mediated education is enacted. These technologies and their associated practices and objects enact environments and ecologies - cyberspaces. For instance, the:

increasingly sophisticated and hyperrealistic graphic representations in video games are able to beckon into being believable environments that possess a genuine sense of spatiality, and often intense sociality, that grips players and pulls them into a compelling ludic realm 'beyond' the screen display. (Dodge, Kitchen, and Zook 2009, 1288)

There are important affective engagements within such spaces. These are often captured in terms of Web 1, Web 2 and now, with the possibilities raised by semantic technologies, the potentiality of Web 3. Computing and software are increasingly pervasive in daily life. Web technology is both hardware and software, which combine in the enacting of space in particular ways through their assemblages with wet- 
ware (i.e. humans), what Dodge, Kitchen, and Zook (2009) refers to as 'code/ space'. In their study of software in people's homes, Dodge and Kitchen (2009) identify the ways in which coded objects, processes, infrastructures and assemblages embedded in everyday life help to enact socio-spatial life, where the virtual remains as 'real' as unmediated face-to-face interaction and is not some entirely separate domain.

In much of the literature there is a shared sense of the centrality of the contribution that the technologies of media, communication and transport have made to spatial orderings (Thompson 2003; McChesney 2003). For some, this signifies a disembedding from the materiality of the local and immediate. Crang, Crosbie, and Graham (2007) argue that much initial discussion of the impact of computer technologies and the Internet was framed within a set of binaries of, for example, the virtual-real, immaterial-material, cyberspace-physical space, with the former posing a threat to the latter. However, these are changing forms of materiality rather than their loss, as the local cannot be assumed to be the realm of the authentic and virtual worlds are not without matter. This is particularly so when we consider the rise of mobile technologies and their capacity to relate people and places across great distances, and places that are themselves mobile, such as cars, trains and planes. Crang, Crosbie, and Graham $(2007,2406)$ point to the ways in which technology is part of and enacted within the everyday, and that technologies are not new in that respect: "online and offline interactions are constituted and constructed together to sustain and transform the complex temporalities and spatialities of everyday urban life". In this respect, as has often been written (for example, Haraway 2003), humans have always been cyborgs. This extends the logic of earlier debates. Morley and Robins, for instance, argued that new technologies

... are implicated in a complex interplay of deterritorialization and reterritorialization ... Things are no longer defined and distinguished in the ways that they once were, by their boundaries, borders or frontiers ... We can say that the very idea of boundary - the frontier boundary of the nation-state, for example, or the physical boundaries of urban structures - has been rendered problematical. $(1995,75)$

Featherstone (1995) points out how frequently metaphors of movement and mobility crop up in the discussion of cyberspaces. There is a sense in which the growth of cyberspaces provides metaphorical vehicles through which there has then been the reconceptualisation of space more generally - emphasising flows, nodes and networks over place and location - even as those notions also inform interpretations of cyberspaces. It is in such conceptions that cyberspaces too easily become a cyber-utopia of openness and democracy - based upon an uncritical concept of mobility. Place, boundedness and the local are positioned as problematic and parochial. This can be found in the uptake of the metaphor of 'flows' contrasted with those of 'positionalities', originating with Deleuze and Guattari and their notion of rhizomatic branching networks as a critique of fixed boundaries and identities. These flows are held to have a deterritorialising effect - of people, images and information, commodities, money and ideas. Unless used carefully, such concepts can result in spatial ideology rather than spatial analysis. The work of Bayne (2004) is careful in this respect. She has drawn from Deleuze and Guattari the contrast between smooth and striated space to analyse digital learning spaces, arguing that they are often more striated than smooth, a point to which we will return when drawing upon the Ensemble data. The important point here is that smooth and stri- 
ated spaces are not either-or but both-and. Mobility through cyberspaces is neither inherently emancipatory nor positive and relies upon its own immobilities and moorings. To more adequately reflect this, Urry $(2007,25)$ uses the concept of flux rather than flow, as "flux involves tension, struggle and conflict".

Kaplan (1996) argues that the new relationship between place and space enabled by new technologies creates new and different networks, communities and subjectivities as more and more people are connected electronically than by conventional geographic proximity. Some of these connectivities are new, some replace the human material face to face and others facilitate the organisation of such interactions. This is a tendency already in place through pre-existing forms of media and communication, such as the television and the telephone, but it is the possibilities for, nature of, and levels of interactivity that are increasing in relation to more traditional broadcast media. Even desktop computers are becoming staid for those who desire the mobility made possible by smart phones, iPads and the like.

\section{Mobilities, mooring and boundings in the uptake of semantic technologies in education}

What tracings of mobilities, immobilities and mooring can we find in the Ensemble project? Methodologically, the approach we are exploring requires detailed ethnographic and ethnomethodological tracing. The data we are drawing upon here is from early engagements with the academics teaching the Plant Sciences course and a participatory design workshop with students and a lecturer in Dance. In both, there was an exploration of that to which they aspired through integrating semantic technologies into their case-based approaches. When introducing the topic to students and lecturers, researchers on the Ensemble project often describe semantic technologies as having the potential to widen access to data and to aggregate information from multiple sources. In relation to learning at university, this could be seen as a process of deterritorialisation of the academic curriculum by opening up different resources upon which to draw. Three inter-related issues emerge strongly from the data, which focus on the degree to which the subject matter can be bound or moored, when the technology enables mobilities that cannot be controlled. These are framed in terms of issues of discipline, pedagogy and identity, but are also about what subjects - knowledge and individuals - are to be assembled in the new spatial (dis)orderings.

The participatory process of technology design in relation to semantic technologies has thus far tended to involve reterritorialisation as boundaries have been renegotiated with lecturers and students and built back into the technology. We draw here upon two examples of technological and pedagogical development in the context of Plant Sciences: technology-led pilot developments of online tools to support learning, and the development of a new module focussing on learning about the production of algal biofuels, using case pedagogy and supported by semantic technologies.

Development in Plant Sciences during the pilot phase of the project focused upon exploring what is possible by applying semantic technologies to examples from Plant Sciences teaching. One project led to the creation of an interactive timeline of plant evolution, exploiting the ability of the technology to draw in numerous datasets, and provide a timeline visualisation for interrogating them. One of the academics identified the importance of the initiative as being for the students to "make better links 
than they were from the traditional way the material is being conveyed". Knowledge is assembled through the linkages made visible in the curriculum practices: "drawing on additional material, pulling it in and using it", as one of the academics puts it. Despite these aspirations, the academic stated the importance of imposing some limitations on the expanse of data and information in order to maintain quality and relevance to the curriculum. The academic emphasised that different boundaries were applicable to undergraduate students in different years:

if we give [students] a certain amount of information you always feel that you have to know everything that has been presented, and so the danger would be that if you gave a [first year] student access to a [third year] learning tool, they might feel that they have to know it all because it was there.

As a result, two different versions of the tool were created for first-year students and a more expansive version for third-years.

Another pilot tool developed at the same time as the timeline sought to support students before and after their field course, which took place in Portugal. In this case, from the outset, the academic cautioned about the potential for being overcome by data ("you've then got this huge diversity which is just too much for anybody to actually handle") and outlined his strategy in dealing with this in his teaching, by dividing it up into three levels (globally, the locality of the Mediterranean, and key examples of plant strategies). In developing the tool, the affordance of semantic technology to be able to incorporate various large datasets actually proved a hindrance, as using the latter to provide a full picture cut across the key teaching objective to provide a small selection of key generalisable examples. As a result, despite positive feedback from Plant Sciences lecturers and students during the development process, the tool was not implemented.

In the example of algal biofuels, development of semantic technologies was concurrent with the pedagogical development of a case-based learning module. At one level, the academics involved wanted to take the students 'out of their comfort zone', a particular location of the familiar to which they were moored. However, this also became a problematic issue for the two academics involved, as when they discussed the possibility of a wiki for the module a tension emerged as to whether it is a bounded container or a space of mobile relations. Is the wiki to be a container within which there are all the resources required for the case study, or is it a node in a wider network wherein the case may be expanded by the searches of the students themselves? For the academics, the negative potential of such mobility is that students may draw in materials that are not valid according to the standards of research upon which the course is based, or they might draw in material that goes beyond or outside the disciplinary expertise of the academic staff involved in teaching the course. The nature and extent of the moorings become a critical issue. For the academics this is tied to issues of disciplinary identity of both the subject and them as subjects - "bounding this activity by being a biologist". This is not to criticise the academics involved for curtailing the 'freedom' of students to be mobile, but rather to trace the (im)mobilities built into what they are enacting and the rationales for them. This is, after all, a biology case study in a Plant Sciences degree. In an Economics degree on energy policy, a different set of moorings would be in play.

There is recognition of this tension by those involved in planning the initiative. If the aim of the semantic case study is to take the students out of their comfort zone, then "keeping this (the case study) focused on the biology is keeping it in the 
comfort zone for the students" (academic). There is thus a pull toward immobility for the students, while the academic staff also wish to push them into extending themselves by creating online links to resources that are beyond their disciplinary home of biology. Curriculum and pedagogy can be framed, therefore, as entailing decisions about the mobility and immobility of subjects and the particular moorings that are enacted through the human and non-human materials that are connected and the forms of connection that both the academics and students make. For example, the academics describe the case-based algal biofuels module in giving the students the 'bigger picture', thinking about how professionals in a biotechnology company would draw different fields into their work, such as economics, chemical engineering and politics, for example. The ability "to synthesise the scientific and other literature and information" is key to the activity. Yet there remains the danger that the mobilities made possible unhinge the desired moorings and could result in the assembling of 'invalid' knowledge or knowledge that goes beyond the bounds of biology as a discipline.

More recent developments for a subsequent iteration of the Algal Biofuels module have been strongly influenced by feedback from students, reviews of the outputs from the previous years and the pedagogical views of the new academic leading the teaching. Initial course aims were "to allow you to gain expert knowledge associated with a real-world issue and get experience of working in a professional way". In this third iteration the module has been refocused to lead to the development of a "scientific proposal' where it is essential that students read the primary literature. It was felt that the previous year's reports showed a 'superficial understanding' of the science behind biofuel production, which may be due to competing disciplinary perspectives diluting the issue in terms of Plant Science. For example, as one academic put it:

there is so much trivia out there you know hype and what do you call it? I mean not science, I mean the commercial side and land use and economics and all that sort of thing that they got side tracked onto that, well didn't get sidetracked but they didn't have the knowledge of the plant biochemistry in order to be able to draw any inferences.

This has led to a restructuring of the semantic technology supporting the module where past student and teacher resources that stand outside the field of biochemistry are not made available and starting references will be kept minimal to encourage independent searching for relevant literature. In other words, the boundaries for the technology have been redrawn along with the pedagogical aims for the module, which moor the case-based learning more closely into a biochemical scientific domain and less into an expansive real-world, professional field.

In Dance, Ensemble were involved with designing a semantic technology to support a telematic dance performed by final-year undergraduates. This provides a second example for this article of how semantic technologies are involved in a deterritorialisation and reterritorialisation of the academic curriculum. However, the territories exemplified here also include physical spaces and bodily movements across different points in time. The dance was performed using video-conferencing software and a large split-screen in the auditorium to link the students in the United Kingdom with another group in the USA. The video-conferencing software and split-screen re-set the physical boundaries of the dance performance to involve several new audiences and new dancers and choreographers who are not physically present. Performances were often videoed from the UK and US perspectives and 
exchanged to allow for a review of past performances from different views. The lecturer/choreographers and student/performers also had multiple roles and identities. However, these roles are traditionally enforced in the discipline of dance and they create moorings for this curriculum. Despite the complexity in space and time, the students always acted as performers whose role was to follow direction from the choreographers and create their own improvisations at the correct points in the performance. They acted as learners and collaborated with the other students/performers, but they rarely crossed over to being teachers or choreographers themselves.

Observation of a review session held with the UK group highlighted the multiplicity of awareness that the students need for their performance. The lecturer acting as choreographer and reviewing a video of the dance from the point of view of the UK audience continually reminded the students to consider all four audiences: the UK live audience, their group, the other (US) group, and their audience. Being able to watch the video from the US point of view was helpful for this. One student commented: "the session where we viewed the footage from the back of the [US auditorium] really opened our eyes to the fact that we were not performing it the way we thought we were at all". It was therefore clear that a semantic technology that could link videos from multiple perspectives, to allow reflection on performances at different times, could support this complex task for multiple users. This would allow students to reach their aim to "appreciate the new effects that we were doing".

Participatory design workshops were held with students and a lecturer from the UK group to initially work out the role and scope of the semantic technology and then to define the ontological structure of the data that it would hold. The first workshop led to a perception of the technology as an environment that would allow both groups to upload pictures and videos of the performance for collaborative review and discussion. This would change the dimensions of time and space for this act of review. Previously it had been restricted to taking place in groups either in the United Kingdom or the USA. It had also only taken place within set times allocated by the lecturer where the students could all be present in the auditorium to watch the performance together. In an online environment the physical boundaries would be broken down, and discussions could take place synchronously or asynchronously related to several different elements and views of the performance. However, this process of critical reflection was currently well supported by the lecturer in the review session. Careful consideration needed to be made for how that scaffolding could be replaced within a more flexible online environment.

The second workshop was related to how pictures or sections of video of the performance could be tagged to enable searching and filtering for different elements to review. Participation of choreographers and performers in this activity enabled the development of a tagging structure that reflected the inherent nature of choreography, disciplinary vocabularies, the performer's physicality and the performance space. In particular, the workshop was essential for classifying terms referred to by the lecturer and students as 'local'. The group developed these terms specifically for this performance. They represented a new vocabulary that was understood by the group to refer to novel group or solo movements and related to the metaphors developed by choreographers for sections of the dance. In this way, spatial elements of the dance were integrated into the ontological data-tagging structure of the semantic technology, which effected the representation of video and photographs of the performance and therefore the reflective process of students in the online envi- 
ronment. This also enforced disciplinary moorings by building in the technical disciplinary vocabulary, which was taught as part of the curriculum in the second year and by stabilising the 'local' terms to create new moorings for the technology and therefore the performance.

It would be a misrepresentation, therefore, to suggest that the semantic technology has broken down spatial and temporal boundaries in this performance and the way upon which it is reflected. The use of an online technology with a semantic data structure allowed for additional spatial and temporal representations of the performance to be accessed and reflected upon by choreographers and performers. However, there are moorings still built into the technology because of the nature of the data and how it is collected as well as the curricular moorings that were built in from participatory design workshops. It is not even necessarily a good pedagogical strategy to break down the boundaries too far, and we have found in both the Plant Sciences and Dance settings that moorings need to build into the technology in order to support undergraduate student learning, even as the possibilities for mobilities grow.

\section{Grounds for mooring}

Some, such as Gough (2004), have experimented with the technological extensions of the human in curriculum and pedagogy, and developed the notion of the learner as cyborg - part-human, part-technology - as a way of formulating the differences in educational practices associated with new technologies. However, it is also possible, drawing on the discussion above, to formulate cyberspace as engendering practices of (im)mobility rather than those of teaching and learning. This entails examining education as a spatio-temporal ordering of mobilising, mooring and boundary marking in the valuing and enacting of certain forms of subjectivities and practices.

Learning is often positioned as the simple service response to globalised complexity and uncertainty. The more challenges and uncertainty in the world, the more one must learn. Learning is represented as a matter of fact for and by humans, a way of representing the objective world to which the separate subject must adapt. The human subject is centred as that which must learn about the world and, as such, is often separated from the world about which they learn. In many ways, participatory theories of learning (for example, Lave and Wenger 1991) have attempted to address this separation focusing on the practices through which people learn. However, this has never been entirely satisfactory due to the under-theorising of participation in relation to wider spatial theory. Learning has remained at the heart of the endeavour, but learning as a concept has evolved from the study of psychology that has at its heart precisely the centring of the human subject.

To suggest a future for education without learning and the knowing subject may seem strange, but that is one possible consequence of examining education and technology spatially. In exploring the uptakes and spatial orderings of cyberspaces, are we perhaps in a position to question learning as being at the heart of education? Learning is often inferred from other practices, thereby centring the subject. Perhaps the (im)mobilities we have outlined and explored above provide a basis through which the subject is decentred, distributed across space and time, yet also gathered through the technological mediations in which humans and non-humans are entangled and moored. To examine education through spatial theory suggests that certain assemblages of the human and non-human enable the enactment of certain practices and representations to be traced. These spatial orderings emerge from certain 
mobilities, moorings and boundary marking, the purposes of which may be other than simply learning and could, as one of us has argued elsewhere (Edwards 2010), be the basis for responsible experimentation. The illustrations from the Ensemble project suggest that the different gatherings enabled by the semantic technologies did support experimentation in the curriculum with different responsibilities to, for instance, students, subject knowledge and identity mooring the possibilities by framing only certain mobilities as legitimate. Here boundary marking is not about putting a fence around a field, but about marking the relations that can be made in specific enactments. Certain branches of spatial theory therefore not only open up particular framings of education and technology, but also raise important curriculum and pedagogic questions about what constitutes a specifically educational assembling and spatial ordering. Such questions are not new in themselves, but we can gather fresh insights through such tracings.

\section{Acknowledgements}

This paper draws upon research funded by the ESRC's Teaching and Learning Programme in Technology Enhanced Learning (RES-139-25-0403). The authors thank the Ensemble team members and the participants in the project.

\section{References}

Anderson, B., and J. Wylie. 2009. On geography and materiality. Environment and Planning A 41: 318-35.

Barad, K. 2007. Meeting the universe halfway. Durham, NC: Duke University Press.

Bayne, S. 2004. Smoothness and striation in digital learning spaces. E-Learning 1, no. 2: 302-16.

Bennett, J. 2010. Vibrant matter: A political ecology of things. Durham, NC: Duke University Press.

Bhabha, H. 1994. The location of culture. London: Routledge.

Brah, A. 1996. Cartographies of diaspora: Contesting identities. London: Routledge.

Braidotti, R. 1994. Nomadic subjects: Embodiment and sexual difference in contemporary feminist theory. New York: Columbia University Press.

Crang, M., T. Crosbie, and S. Graham. 2007. Technology, time-space, and the remediation of neighbourhood life. Environment and Planning A 39: 2405-22.

Deleuze, G., and F. Guattari. 1988. A thousand plateaus. London: Athlone.

Dodge, M., and R. Kitchen. 2009. Software, objects and home space. Environment and Planning A 41: 1344-65.

Dodge, M., R. Kitchen, and M. Zook. 2009. How does software make space? Exploring some geographical dimensions of pervasive computing and software studies. Environment and Planning A 41: 1283-93.

Edwards, R. 2010. The end of lifelong learning? A post-human condition. Studies in the Education of Adults 42: 5-18.

Edwards, R., and R. Usher. 2008. Globalisation and pedagogy: Space, place and identity. 2nd ed. London: Routledge.

Edwards, R., K. Nicoll, N. Solomon, and R. Usher. 2004. Rhetoric in educational discourse. London: Routledge.

Elden, S. 2001. Politics, philosophy, geography: Henri Lefebvre in recent Anglo-American scholarship. Antipode 33: 809-25.

Featherstone, M. 1995. Undoing culture: Globalisation, postmodernism and identity. London: Sage.

Ferrare, J., and M. Apple. 2010. Spatialising critical education: Progress and cautions. Critical Studies in Education 51, no. 2: 209-21.

Gough, N. 2004. RhizomANTically becoming-cyborg: Performing posthuman pedagogies. Educational Philosophy and Theory 36, no. 3: 253-65.

Gulson, K., and C. Symes. 2007. Spatial theories of education. London: Routledge. 
Hannam, K., M. Sheller, and J. Urry. 2006. Editorial: mobilities, immobilities and moorings. Mobilities 1, no. 1: 1-22.

Haraway, D. 2003. Interview with Donna Haraway. In Chasing technoscience: Matrix for materiality, ed. D. Ihde and E. Selinger. Bloomington and Indianapolis: Indiana University Press.

Harvey, D. 1989. The condition of postmodernity: An enquiry into the origins of social change. Oxford: Basil Blackwell.

Jones, G., C. McLean, and P. Quattrone. 2004. Spacing and timing. Organisation 11, no. 6: 723-41.

Kaplan, C. 1996. Questions of travel. London: Duke University Press.

Lankshear, C., M. Peter, and M. Knobel. 1996. Critical pedagogy and cyberspace. In Counternarratives, ed. H. Giroux et al., 149-88. New York: Routledge.

Lave, J., and E. Wenger. Situated learning. Cambridge, UK: Cambridge University Press.

Lefebvre, H. 1991. The production of space. Oxford: Blackwell.

Licoppe, C. 2004. 'Connected' presence: The emergence of a new repertoire for managing social relationships in a changing communication technoscape. Environment and Planning D: Society and Space 22: 135-56.

Massey, D. 1993. Politics and space/time. In Place, the politics of identity, ed. M. Keith and S. Pile, 141-61. London: Routledge.

Massey, D. 1994. Space, place and gender. Cambridge: Polity Press.

McChesney, R. 2003. The new global media. In The global transformations reader, ed. D. Held and A. McGrew, 260-8. Cambridge: Polity Press.

Morley, D., and K. Robins. 1995. Spaces of identity: Global media, electronic landscapes and cultural boundaries. London: Routledge.

Murdoch, J. 1998. The spaces of actor-network theory. Geoforum 29, no. 4: 357-74.

Nespor, J. 1994. Knowledge in motion. London: Falmer.

Sheller, M., and J. Urry. 2006. The new mobilities paradigm. Environment and Planning A 38: 207-26.

Shields, R. 1999. Lefebvre, love and struggle: Spatial dialectics. London: Routledge.

Soja, E. 1989. Postmodern geographies: The reassertion of space in critical social theory. London: Verso.

Soja, E., and B. Hooper. 1993. The spaces that difference makes: Some notes on the geographical margins of the new cultural politics. In Place, the politics of identity, ed. M. Keith and S. Pile, 183-205. London: Routledge.

Spivak, G. 1993. Outside in the teaching machine. London: Routledge.

Thompson, J. 2003. The gloablisation of communication. In The global transformations reader, ed. D. Held and A. McGrew, 246-59. Cambridge: Polity Press.

Urry, J. 2007. Mobilities. Cambridge: Polity Press.

Watts, L., and J. Urry. 2008. Moving methods, travelling times. Environment and Planning D: Society and Space 26: 860-74. 